1 Universidade Federal da Bahia (UFBA), Instituto de Saúde Coletiva (ISC) Salvador (BA), Brasil. andretj@terra.com.br

\section{Análise dos programas das coligações majoritárias apresentados às eleições de 2014 e a Reforma Sanitária Brasileira}

Analysis of the programs of majority coalitions presented at the 2014 elections and the Brazilian Health Reform

André Teixeira Jacobina'

RESUMO O objetivo deste trabalho foi analisar a visão das três coligações mais votadas nas eleições presidenciais em 2014, buscando identificar aproximações e distanciamentos ao projeto da Reforma Sanitária Brasileira (RSB). Utiliza como fontes os programas registrados no Tribunal Superior Eleitoral (TSE) e suas atualizações disponibilizadas nas páginas eletrônicas das candidaturas e as propostas do movimento da RSB, sistematizadas no Relatório da VIII Conferência Nacional de Saúde, de 1986. Conclui-se que os programas das três coligações, com variações, aderem à perspectiva neodesenvolvimentista, distinta das perspectivas liberal, social-democrata e socialista. Consideram que o Estado deve intervir para garantir a expansão do consumo e a reprodução do capital, concepção diversa da RSB que defende o direito à saúde e o acesso universal aos serviços, com estatização progressiva do sistema de saúde, evidenciando-se o distanciamento entre os programas apresentados e os princípios, diretrizes e valores que embasam o processo de RSB.

PALAVRAS-CHAVE Reforma dos serviços de saúde. Política. Sistema Único de Saúde.

ABSTRACT The aim of this work was to analyze the vision of the three most voted coalitions in the presidential elections in 2014, seeking to identify approximations and distances regarding the Brazilian Health Reform (RSB) project. It uses as sources the programs registered in the Superior Electoral Court (TSE) and its updates available in the electronic pages of the candidacies and the proposals of the movement of the RSB, systematized in the Report of the 8th National Health Conference, of 1986. We conclude that the programs of the three coalitions, with variations, adhere to the neodevelopmental perspective, distinct from the liberal, social-democratic and socialist perspectives. They consider that the State should intervene to ensure the expansion of consumption and reproduction of capital, a different conception of the RSB that defends the right to health and universal access to services, with progressive nationalization of the health system, evidencing the distance between the Programs presented and the principles, guidelines and values that sustain the RSB process.

KEYWORDS Health care reform. Politics. Unified Health System. 


\section{Introdução}

O debate contemporâneo sobre a Reforma Sanitária Brasileira (RSB) aponta a existência de uma controvérsia acerca de sua vitalidade e permanência na conjuntura atual. Alguns autores, como Hochman (2013), consideram que a RSB se limitou ao período de transição democrática, enquanto outros, como Paim (2013), defendem que o processo de RSB não terminou, o que pode ser evidenciado pela formulação da Agenda Estratégica para a Saúde (AGENDA, 2011), pela militância do Centro Brasileiros de Estudos de Saúde (Cebes) e pela mobilização dos participantes dos Conselhos e das Conferências de Saúde. A existência dessa controvérsia estimula a realização de estudos sobre o posicionamento político de distintos sujeitos com relação à RSB, a exemplo de organizações sindicais, associações profissionais, entidades religiosas e partidos políticos.

O interesse específico é com as coligações que disputaram as eleições de 2014, entre as quais focou-se nas coligações majoritárias, usando como critério de seleção o desempenho eleitoral. Desse modo, este trabalho tem por objetivo analisar os programas de governo das coligações que apresentaram as candidaturas de Dilma Rousseff, Aécio Neves e Marina Silva, buscando responder às seguintes perguntas: quais as perspectivas adotadas por cada coligação em relação ao papel do Estado na área econômica e social? Qual a proposta com relação à participação política? Qual a proximidade e o distanciamento das propostas para a Saúde em relação ao projeto da RSB?

\section{Fontes e referencial para análise política dos programas das coligações partidárias}

A literatura sobre a relação entre Movimentos Sociais (MS) e Partidos Políticos (PP) destaca a autonomia dos primeiros, problematiza a influência dos partidos ou analisa em que medida movimentos influenciam partidos e vice-versa. Da revisão efetuada, vale a pena destacar o trabalho de Ruscheinsky (1999) que apresenta uma reflexão sobre a relação entre MS e PP, nos anos 1980 e 1990 no Brasil, utilizando diversas fontes; e o de Moreira (2000) que compara a trajetória política e as articulações da Frente Ampla uruguaia e do Partido dos Trabalhadores (PT) no Brasil com os MS e destaca em ambos o forte vínculo com o movimento sindical e a vocação política governamental (JACOBINA, 2016).

Especificamente na área de saúde, as propostas das coligações que concorreram às eleições em 2014 foram analisadas por Bahia e Schefer (2014) e Magno (2015). Optouse, entretanto, por analisar o programa de cada coligação como um todo, e não apenas as propostas para a saúde. Os documentos foram coletados no site do Tribunal Superior Eleitoral (TSE) e nas páginas oficiais dos partidos líder de cada coligação. Na análise de cada programa, tratou-se de identificar a perspectiva política - liberal, 'gerencialista', e social-democrata - que impregna cada documento.

A perspectiva liberal defende a redução do papel do Estado, em especial na esfera econômica, partindo do entendimento que o setor privado é mais eficiente, sendo preferível que tome as rédeas do processo produtivo e tenha liberdade para tanto (BOBBIO, 2001).

A perspectiva gerencialista considera que tanto o setor privado quanto o setor estatal têm responsabilidades sobre o desenvolvimento econômico e atribui ao Estado o papel de mediador, 'gerente' (regulador) da produção, sendo produtor apenas quando necessário (BRESSER-PEREIRA, 1998). Essa perspectiva deriva em parte do neodesenvolvimentismo, corrente de pensamento que defende um Estado forte, interventor, regulador, mas a favor do mercado, entendido como gerador de riquezas a serem utilizadas em programas sociais voltados aos mais pobres, com 
vistas à ampliação do mercado interno. A industrialização e a inovação adquirem uma importância central, dando-se ênfase ao progresso técnico e à inserção do País no cenário internacional (BOSCHI; GAITÁN, 2013).

A perspectiva social-democrata, por sua vez, assume uma concepção de 'Estado de bem-estar social', responsável pela garantia dos direitos sociais, entre os quais o direito à saúde, princípios e valores que historicamente foram assumidos por PP 'de esquerda', a exemplo da social-democracia europeia e partidos de matriz socialista, que defendem o fortalecimento e ampliação do papel do Estado na economia, enquanto produtor e provedor de serviços, visando à distribuição de renda e redução das desigualdades sociais. Essa perspectiva é coerente com o projeto da RSB, que assume uma concepção ampliada de saúde, propõe o desenvolvimento e ações intersetoriais de promoção e melhoria da qualidade de vida, garantia do acesso a serviços e ampliação da participação social na gestão pública (PAIM, 2008).

Além disso, tratou-se de explicitar o que se chama 'espectro político', partindo da revisão dos termos 'esquerda' e 'direita', palavras que não designam conteúdos fixos, sendo conceitos relativos que apontam lugares no 'espaço político'. Assumiu-se, como critério para efetuar essa distinção, a noção de igualdade, considerando que um partido está tanto mais à esquerda quanto mais incluir em seu programa propostas igualitárias; e, ao contrário, quanto menos se comprometer com valores igualitários, mais à direita estará. Nesse sentido, se um partido defender a democratização do Estado e do acesso a bens e serviços e propugnar pela garantia dos direitos sociais, mais à esquerda estará. Se defender um sistema de saúde regulado pelo mercado, no qual o acesso aos serviços depende do poder aquisitivo dos diversos grupos da população, mais à direita estará. Combinando as definições de esquerda e direita com a visão acerca do Estado, considera-se que, à direita, tem-se a perspectiva liberal, ao centro, a neodesenvolvimentista, que oscila entre centro-esquerda ou centro-direita, e, à esquerda, a perspectiva social-democrata e a socialista, que defendem maior igualdade tanto material quando de poder (BOBвIO, 2001).

\section{Projeto da RSB}

O projeto da RSB pode ser apreendido, em suas linhas gerais, no Relatório da VIII Conferência Nacional de Saúde (CNS) que apresenta uma concepção ampliada de saúde e defende a saúde enquanto direito, entendido como:

[...] a garantia, pelo Estado, de condições dignas de vida e de acesso universal e igualitário às ações e serviços de promoção, proteção e recuperação de saúde, em todos os seus níveis, e todos os habitantes do território nacional, levando ao desenvolvimento pleno do ser humano em sua individualidade. (CNS, 1986, P. 11).

Com relação ao sistema de saúde, o Relatório aponta que a proposta de estatização imediata foi recusada, havendo "consenso sobre a necessidade de fortalecimento e expansão do setor público" e que "a participação do setor privado deve-se dar sob o caráter de serviço público 'concedido' ao contrato regido sob as normas do Direito Público" (CNS, 1986, P. 11). Chama a atenção que

a previdência social deve se encarregar das ações próprias de 'seguro social' (pensões, aposentadorias e demais benefícios) e a saúde deve ser entregue, em nível federal, a um único órgão com características novas (CNS, 1986, P. 11),

e o seu financiamento deveria contemplar um orçamento próprio, proveniente de "várias receitas, oriundas de impostos gerais e incidentes sobro produtos e atividades nocivas à 
saúde”, destacando também a importância da participação popular (CNS, 1986, P. 11).

O essencial do projeto é, portanto, a defesa do direito à saúde, a responsabilidade do Estado em garanti-lo, a proposta de unificação do sistema público, o financiamento próprio e a gestão participativa, coerente com a noção de democratização da saúde, base conceitual e política do movimento pela RSB. As propostas aprovadas indicam que não estavam dadas as condições políticas para uma estatização do sistema público e apontam a adoção de um posicionamento de esquerda social-democrata, visando à construção de sistema de saúde aproximado ao que prevalece no Estado de bem-estar social. Ainda que uma análise mais detalhada possa evidenciar as tensões e divergências internas ao movimento, o Relatório da VIII CNS constitui um marco do consenso construído naquele momento e pode ser tomado como referencial político para a análise dos programas das candidaturas à presidência em 2014 (CNS, 2011; PAIM, 2008).

\section{Programa da coligação Muda Brasil (PSDB/PMN/ SD/DEM/PEN/PTN/PTB/ PTC/PT do B)}

O programa da coligação liderada pelo Partido da Social Democracia Brasileira (PSDB) defende que as regiões mais fragilizadas economicamente do Brasil recebam tratamento especial por meio de programas e projetos de fomento econômico, dá forte prioridade à micro e pequenas empresas e destaca a necessidade de investir em Ciência e Tecnologia (C\&T), afirmando que "desenvolvimento significa elevar a capacidade de inovação tecnológica do país" (BRASIL, 2016, P. 30).

O texto contém uma série de diretrizes, a exemplo da ampliação dos movimentos de cooperação e diálogo entres os setores público e privado como o MEl (Movimento Empresarial para Inovação), incluindo representantes acadêmicos e de centros tecnológicos, empreendedores e lideranças empresariais de pequenas e médias empresas. (BRASIL, 2016, P. 32).

Destaca a necessidade de promover uma crescente integração do Brasil no comércio internacional a partir da integração competitiva das empresas brasileiras às cadeias mundiais de valor, o que implica redução da tributação sobre exportações, simplificação "da legislação de comércio exterior e desburocratização das aduanas e portos" (BRASIL, 2016, P. 33).

Defende o cumprimento inequívoco dos compromissos do tripé macroeconômico: "redução da inflação superávit primário obtido sem artifícios contábeis e câmbio flutuante" (BRASIL, 2016, P. 44), visando "reduzir incerteza e ampliar segurança para investimentos", propondo também "a autonomia operacional ao Banco Central", instituição que "deverá suavizar as flutuações do ciclo econômico e zelar pela estabilidade financeira” (BRASIL, 2016, P. 44), enfatizando que a carga tributária é elevada e deve ser reduzida e simplificada. Um discurso, nesse momento do programa, bem liberal.

As ideias neodesenvolvimentista também estão presentes, como a defesa de inovação, competitividade no mercado mundial, presença de um Estado forte, a serviço do capitalismo nacional. Quanto à gestão do Estado, defende a profissionalização e a valorização do mérito, mas não menciona a diminuição do número de cargos de confiança. Defende a desburocratização e o fortalecimento do controle social, propondo a abertura de canais para o diálogo com o cidadão que queira interagir com o Poder Público, e afirma que

o governo federal deve estimular o debate e a busca de consensos por meio da participação social de grupos, coletivos, organizações não-governamentais, movimentos sociais e populares (TSE, 2014, P. 24) 
e prestigiar "os Conselhos Nacionais de políticas públicas” (TSE, 2014, P. 24).

No que tange à saúde, destaca ações realizadas na gestão de Fernando Henrique Cardoso (FHC), quais sejam:

[...] a descentralização da gestão e do financiamento dos recursos federais para os estados e municípios, iniciando as transferências financeiras 'fundo a fundo', o Programa Saúde da Família, os medicamentos genéricos, a estruturação do controle social, mecanismos de controle e avaliação, entre outras. (TSE, 2014, P. 58).

Critica a baixa remuneração no setor e o reduzido orçamento da seguridade social, comentando que, apesar do aumento da participação dos estados e municípios, o financiamento da Saúde é insuficiente. Defende, assim, os preceitos da Emenda Constitucional 29, nos percentuais dos pisos mínimos estabelecidos por lei para estados e municípios, e a proposta popular dos 10\% da Receita Corrente Bruta da União para o setor saúde ou política similar que garanta um crescimento progressivo de financiamento para o setor (TSE, 2014).

Com relação ao Sistema Único de Saúde (SUS), o programa apresenta propostas, como o ‘cartão-cidadão', para acesso à rede pública e privada, o investimento em tecnologias de informação, um novo modelo de gestão de redes integradas de saúde, um modelo assistencial com foco no paciente e na continuidade do cuidado em todos os níveis e a instituição da carreira nacional dos médicos. Nesse particular, defende a aplicação do Revalida aos médicos estrangeiros e o fornecimento de cursos preparatórios, como forma de aprimorar o programa 'Mais Médicos'.

O Programa Saúde da Família (PSF) é caracterizado como "porta de entrada do SUS" devendo ser aprimorado a fim de que atenda a todas as necessidades de promoção, prevenção e atenção básica da população brasileira (TSE, 2014, P. 59). Também aponta as reclamações da população usuária dos planos de saúde, que representam 25\% da população brasileira, com a desigualdade no acesso e na qualidade dos planos (TSE, 2014, P. 60), propondo o "fortalecimento", "modernização", e "profissionalização" da Agência Nacional de Saúde Suplementar (ANS). Defende, entretanto, a

integração do sistema de saúde suplementar com o SUS, para identificar oportunidades de colaboração e investimento e desenvolvimento de parcerias público-privadas (TSE, 2014, P. 60),

não reconhecendo a contradição entre os sistemas e os embates dessas lógicas distintas.

Apresenta, ainda, propostas para o aperfeiçoamento da gestão do SUS sugerindo a autonomia de gestão em todos os níveis das redes de saúde, definição e uso de protocolos, padrões de qualidade e processos otimizados para os controles internos, e otimização do modelo assistencial, com iniciativas que incentivem a desospitalização e a profissionalização do cuidado. O problema central da gestão (PAIM; TEIXEIRA, 2007) expresso na manutenção do clientelismo, fisiologismo e o excesso de cargos de confiança, em suma, o problema do patrimonialismo do Estado brasileiro, porém, não é abordado.

Por fim, destaca o combate a diversos problemas de saúde, como envelhecimento da população, obesidade, doenças cardiovasculares, câncer, traumatismos, envenenamentos, doenças respiratórias; diabetes e hipertensão, uso/abuso de drogas lícitas e ilícitas (sem referir-se à descriminalização ou legalização). Defende o programa de controle do Vírus da Imunodeficiência Humana/ Síndrome da Imunodeficiência Adquirida (HIV/Aids) e o combate ao tabagismo, assim como o fortalecimento de ações de promoção da saúde e de hábitos saudáveis de vida, a adoção de tecnologias sustentáveis, a melhoria das condições de trabalho, a

ampliação do complexo produtivo da saúde, [...], desenvolvimento da política de ciência, tecnologia e inovação e o fortalecimento da 
indústria farmacêutica nacional e dos laboratórios farmacêuticos oficiais. (TSE, 2014, P. 62).

\section{Programa da coligação Unidos pelo Brasil (PHS/ PRP/PPS/PPL/PSB/PSL)}

O documento da coligação liderada pelo Partido Socialista Brasileiro (PSB) apresenta inicialmente um diagnóstico da situação econômica do País, elogiando a estabilidade alcançada com o Plano Real e a implementação de políticas sociais de educação, saúde e transferências de renda, combinadas com o crescimento econômico. Entende, porém, que desafios fundamentais não foram enfrentados e aponta a necessidade de aperfeiçoar o ambiente de negócios no Brasil a fim de mobilizar o investimento privado com critérios claros de regulação (BRASIL, 2016). Além disso, sinaliza que apesar de a

carga tributária ter se mantido em nível elevado (mais de $37 \%$ do Produto Interno Bruto - PIB em 2013), os investimentos do governo federal têm ficado em patamares baixos. (BRASIL, 2016, P. 42).

Além dessas propostas, que aproximam o programa da perspectiva gerencialista, outros trechos ecoam a perspectiva liberal como a crítica às políticas adotadas no governo Dilma para setores econômicos específicos, por "provocarem distorções de preços e má alocação de recursos", sugerindo "simplificar a estrutura tributária, reduzindo o número de impostos e tornando os procedimentos mais simples" (BRASIL, 2016, P. 48), "a não-elevação da carga tributária", "redução dos impostos sobre faturamento de empresas"; "desoneração de investimentos" e "desarme da guerra fiscal" com "melhor repartição das receitas entre os entes federados (BRASIL, 2016, P. 50). Defende também a independência do Banco Central o mais rapidamente possível, para que ele possa praticar a política monetária necessária ao controle da inflação (BRASIL, 2016).

A defesa da autonomia do Banco Central e o reconhecimento dos pesados impostos sobre empresas parecem resultar da influência do setor empresarial dentro do partido. Todavia o programa também sofre outras influências, de modo que defende uma economia sustentável do ponto de vista socioambiental e valoriza a universalização e a garantia dos direitos sociais. Nesse sentido, defende mudanças nas regras que regulam as relações entre empresas e empregados para ampliar a proteção aos trabalhadores, manter os direitos conquistados e criar um ambiente de maior segurança jurídica (BRASIL, 2016).

Sobre o papel do Estado, destaca que vai "inverter a lógica dominante nos últimos quatro anos" (BRASIL, 2016, P. 44), indicando que "a mudança passa por elevar progressivamente a responsabilidade dos atores da política - mandatários, legisladores e cidadãos", "mudanças na forma de atuação do governo e das estatais" (BRASIL, 2016, P. 12) e "apoio a municípios por uma administração com foco em resultados, metas, indicadores e bonificação por desempenho" (BRASIL, 2016, P.18). Além disso, sob o lema "democratizar a democracia", elenca uma série de propostas de reforma política:

Unificação do calendário geral das eleições, fim da reeleição e adoção do mandato de cinco anos; adoção de novos critérios na definição da ordem dos eleitos para cargos proporcionais [...]; inscrição de candidaturas avulsas aos cargos proporcionais [...]. Redefinição da distribuição do tempo de propaganda eleitoral gratuita com base em novos critérios [...] convocação de plebiscitos e referendos pelo povo e facilitar a iniciativa popular de leis, mediante redução das assinaturas necessárias e da possibilidade de registro de assinaturas eletrônicas; fortalecimento dos mecanismos de transparência nas doações para campanhas eleitorais. (BRASIL, 2016, P. 15). 
O financiamento das campanhas é criticado desde que o financiamento privado dos partidos resulta em competição com base em condições desiguais e conduz à "apropriação da política por interesses econômicos como matriz dos escândalos”. Entretanto, o programa reafirma que "doar fundos a um partido constitui livre exercício de um direito político" e apenas comenta que é preciso atentar para o princípio da equidade entre os cidadãos, dada a grande diferença entre a capacidade contributiva de cada um (BRASIL, 2016, P. 15).

Critica a aprovação, em 2013, da Minirreforma Eleitoral, que "privilegia os grandes partidos” (BRASIL, 2016, P. 16) e destaca que reformar o sistema de financiamento político-partidário requer devolver ao cidadão sua capacidade de exercer influência nas instâncias de escolha política dos representantes, de forma equânime (BRASIL, 2016).

Em relação à Saúde, o $\mathrm{PSB}$ reconhece o subfinanciamento do SUS, defendendo o projeto de lei de iniciativa popular de vincular 10\% da Receita Corrente Bruta da União ao financiamento da saúde. Enfatiza a Estratégia Saúde da Família como 'porta de entrada' para os serviços de saúde, propondo universalizar o PSF, ampliar a atenção domiciliar e oferecer às suas equipes retaguarda de apoio, com policlínicas, maternidades e hospitais distribuídos em todas as regiões. Também propõe construir cem hospitais voltados para o atendimento regional, possibilitando a incorporação dos leitos perdidos pelo SUS ao longo dos últimos anos (BRASIL, 2016).

\section{Programa da coligação com a força do povo (PT/PMDB/ PSD/PP/PR /PROS/PDT/ PCdoB /PRB)}

O programa da coligação liderada pelo PT reafirma políticas, programas e projetos implementados pelos governos petistas no período anterior. Ressalta a importância dos investimentos em produção e consumo de massa, em infraestrutura social e econômica, na construção de um Brasil sem burocracia e nas áreas de educação, ciência, tecnologia e inovação, construindo uma sociedade do conhecimento. Como o PSDB e o PSB, o PT propõe estímulo ao empreendedorismo e diminuição de burocracia, enfatiza as parcerias entre Estado e iniciativa privada, mas também destaca a necessidade de rigor da gestão fiscal, e ampliação do investimento público (BRASIL, 2016).

A perspectiva neodesenvolvimentista aparece em propostas que enfatizam a

modernização do parque industrial brasileiro, pela melhoria no ambiente de negócios e pela maior capacitação de nossas empresas e da qualificação de nossa mão de obra (BRASIL, 2016, P. 2),

bem como na ênfase atribuída à qualificação do mercado interno e a visão de que os programas de transferência de renda contribuem, em conjunto com outras políticas sociais, como aumento do salário mínimo, para o fortalecimento desse mercado. Assim, o programa reafirma a importância do tripé macroeconômico e destaca os objetivos do novo governo:

[...] continuidade e fortalecimento das políticas sociais, e busca permanente do crescimento econômico inclusivo e sustentável, promovendo a competitividade produtiva e assumindo a garantia de acesso à educação de qualidade como grande motor da transformação [...] o novo ciclo histórico que propomos ao Brasil passa pelas reformas política, federativa, urbana e dos serviços públicos. (BRASIL, 2016, P. 2).

Quanto à Reforma Política, o programa aponta a necessidade de melhorar a representatividade política, aprimorar o sistema eleitoral, tornar a política mais transparente, e defende a realização de um plebiscito como instrumento de participação popular a fim de definir a posição majoritária sobre os principais temas, chamando a atenção para que "o 
combate sem tréguas à corrupção deve fazer parte da urgente transformação do sistema político e eleitoral brasileiro" (BRASIL, 2016, P. 18). $\mathrm{O}$ programa não aborda, porém, a questão das volumosas contribuições empresariais ao financiamento das campanhas, e o poder desses setores, diz apenas que é preciso oxigenar o sistema eleitoral, definindo regras claras de financiamento (BRASIL, 2016).

Expressa o desejo de ampliar a democracia política como algo que andaria junto da democracia econômica (distribuição de renda e eliminação da pobreza), mas a única proposta com relação a isso é a institucionalização do Sistema Nacional de Participação Popular, que "terá a função de consolidar as formas de participação colocadas em prática nos governos Lula e Dilma" (TSE, 2014, P. 20), proposta que estava tramitando no Congresso no período eleitoral e foi derrotada no final de 2014.

No que tange à saúde, destaca a melhoria das condições de saúde da população, atribuindo-a à expansão das ações e serviços garantidos pelo SUS, à implementação de políticas sociais de combate à pobreza e ao aumento do acesso a esgoto e água tratada durante os Governos Luiz Inácio Lula da Silva e Dilma Rousseff (TSE, 2014, P. 13), e apresenta como projetos prioritários:

[...] a expansão do Programa Mais Médicos (PMM); a ampliação da rede de Unidades de Pronto Atendimento (UPAs); a extensão das redes de atendimento especializado, com a qualificação dos serviços hospitalares; o fortalecimento e a universalização do Samu e a ampliação do acesso da população a medicamentos. (TSE, 2014, P. 22).

É importante notar que não existe menção à Estratégia Saúde da Família, tema central nas propostas de governos anteriores, inclusive do Governo Lula (TEIXEIRA; PAIM, 2005). Além da ênfase na implantação de UPA e no PMM, o programa reproduz uma perspectiva de políticas sociais focalizadas, incorrendo no risco de reduzir o SUS a um 'SUS para pobres' (PAIM, 2012), mesmo que aponte que o SUS tem cumprido um importante papel na universalização do acesso e que reafirme o

compromisso com seu contínuo fortalecimento e aprimoramento, necessário devido a seu tamanho, à extensão dos serviços envolvidos e às sobreposições de atribuições entre os entes federativos. (PAIM, 2012, P. 23).

Apesar disso, o programa é sucinto no que diz respeito ao financiamento do setor e assinala apenas que a melhoria no atendimento e o aumento da rede de saúde

exigirão uma rediscussão federativa, que terá o poder de evitar superposição de investimentos e de planejar com mais eficiência a distribuição dos serviços de saúde públicos. (TSE, 2014, P. 22).

Não se refere ao projeto de iniciativa popular que cobra a destinação de $10 \%$ $($ Saúde +10$)$ das receitas da União para a saúde, nem aponta fontes alternativas que poderiam contribuir para a superação do subfinanciamento, a exemplo da taxação sobre as grandes fortunas. A dúvida que fica, portanto, é a que SUS o programa se refere, se é o SUS idealizado pelo movimento da RSB, cuja construção vem enfrentando enormes dificuldades ao longo das últimas décadas, ou se o partido se rendeu a uma perspectiva racionalizadora (PAIM, 2013A), que conjuga a expansão de serviços básicos para os 'pobres', com a reprodução ampliada dos interesses do capital privado investido no setor (BAHIA, 2005), tanto na produção de serviços e insumos quanto na gestão dos estabelecimentos de maior complexidade, a exemplo dos hospitais (COSTA, 2013).

\section{Discussão}

Os programas das coligações lideradas pelo PSB, PSDB e PT tentam, de diferentes 
formas, contemplar interesses contraditórios, provavelmente em busca de alargamento de suas bases de apoio. Esse artifício, entretanto, confere a cada programa uma aparência de 'colcha de retalhos', que pode induzir à conclusão de que não são documentos coerentes. Uma análise mais apurada, entretanto, evidencia que esses programas têm mais em comum do que diferenças substantivas. Todos reconhecem que o Estado tem o papel de promover o crescimento econômico, preenchendo os vazios do mercado, corrigindo suas assimetrias e atuando nos espaços que não interessam diretamente ao setor privado. Defendem o empreendedorismo, o ajuste fiscal, o aperfeiçoamento da gestão pública e reconhecem a importância da atuação estatal na área social. Em outras palavras, todos adotam uma perspectiva neodesenvolvimentista e gerencialista e, apesar do que apresentam em suas siglas, tendem a afastar-se da perspectiva social-democrata, apresentando propostas de políticas sociais compensatórias, focalizadas nos 'pobres', aos quais é oferecida a inclusão social pelo consumo de serviços produzidos por meio de parcerias público-privadas.

As diferenças entre os programas são sutis e consistem na ênfase em determinadas opções estratégicas do que em termos de objetivos. Assim, o programa da coligação liderada pelo PSB é mais enfático na proposta de independência do Banco Central, proposta cara aos setores liberais. O programa da coligação liderada pelo PSDB é o que defende mais enfaticamente a incorporação de inovações tecnológicas na produção. $O$ programa da coligação liderada pelo PT é o mais cheio de 'marcas' de programas federais voltados ao combate à pobreza. Essas diferenças parecem refletir o atendimento de demandas específicas de setores que compõem a base de apoio de cada partido, o que explica, em parte, as ambiguidades e contradições, já que as bases desses partidos não são homogêneas e abrigam grupos com interesses diversos e até antagônicos.
Ao utilizar critérios próprios de análise, percebe-se que o programa da coligação liderada pelo PSDB se encaixa mais em uma perspectiva de centro-direita, especialmente pela sua defesa do empreendedorismo, das parcerias público-privadas, embora não defenda explicitamente a redução do papel do Estado, e sim a redefinição de suas relações com o setor privado.

Já o programa da coligação liderada pelo PSB é dos mais difíceis de classificar. No capítulo de economia, o programa é de centro-direita, e nos capítulos relativos à saúde, educação e reforma política, é de centro-esquerda, até por defender, ainda que esta proposta soe meramente retórica, a necessidade de uma 'democracia de alta intensidade'.

O programa da coligação liderada pelo $\mathrm{PT}$ trabalha com a noção de que garantir acesso ao consumo para todos pressupõe focalizar políticas e projetos nos mais pobres, seja fornecendo diretamente os serviços, seja facilitando o crédito, de modo que estes venham a consumir serviços públicos ou passem a comprar serviços no setor privado. Situase, predominantemente, em uma posição de centro-esquerda, oscilando para uma posição de centro-direita quando trata de parcerias com a iniciativa privada, aproximando-se assim da perspectiva adotada pelo PSDB, embora este pareça se apoiar mais em uma aliança com o capital internacional, enquanto o PT enfatiza uma aliança com o setor privado nacional.

Todos os programas se situam, portanto, em torno do centro político, cabendo ressaltar que este 'centro' se caracteriza, fundamentalmente, pela subordinação do Estado às políticas de ajuste macroeconômico, visando à manutenção das condições de reprodução do capital, ante a crise internacional, cujos efeitos se fizeram sentir mais recentemente sobre a economia brasileira. No que se refere às políticas sociais e à participação social, os programas oscilam um pouco mais à direita ou um pouco mais à esquerda, enfatizando a 'radicalização da 
democracia' (PSB) ou a 'institucionalização da participação social' (PT), sem se comprometerem com uma ampla reforma do sistema político brasileiro, como se depreende da timidez com que tratam o financiamento das campanhas eleitorais que é a questão central, por essa perspectiva, quando se fala em ampliar a democracia ou radicalizar a democracia (SINGER, 2015).

Com isso, percebe-se que os programas dessas coligações, que, certamente expressam as visões dos partidos que as lideram, distanciam-se das propostas da RSB. Levando em conta o que foi aprovado no Relatório da VIII CNS, constata-se que nenhum deles defende uma concepção ampliada de saúde, limitando suas propostas ao 'fortalecimento do SUS', sem explicitar claramente como pensam superar os obstáculos enfrentados no processo de construção desse sistema, ou seja, o subfinanciamento, o patrimonialismo do Estado brasileiro umbilicalmente ligado à má qualidade da gestão pública e à manutenção do modelo médico assistencial hospitalocêntrico, apresentando propostas que fortalecem o processo de privatização do sistema e a implantação de programas que representam 'mais do mesmo' do que tem sido feito em gestões anteriores (TEIXEIRA; SOUZA; PAIM, 2014).

\section{Considerações finais}

Este trabalho evidencia que, apesar de toda ilusão que perpassa o teatro político, os programas de governo podem ser fontes de pesquisa, permitindo a identificação das ideologias que influenciam a direção adotada pelos partidos coligados e a distância entre as demandas e propostas dos MS e os programas de partidos supostamente de esquerda. Cabe, entretanto, apontar os limites deste trabalho, uma vez que, para aprofundar a compreensão das posições políticas dos partidos analisados, seria necessário ir além do discurso dos programas e analisar a relação das lideranças com a base social de cada partido, bem como as alianças que se estabelecem ao longo do processo político eleitoral. Os discursos dos programas das coligações partidárias não devem, portanto, ser vistos isoladamente, desde que, como diria o historiador marxista Thompson (1981), não cabe interrogar as palavras em si mesmas, mas o significado que assumem quando utilizadas pelos sujeitos da história.

Um aspecto, entretanto, parece relevante destacar. A análise dos programas parece, à primeira vista, validar a afirmação do cientista político Bolívar Lamounier (2015), de que não há direita no Brasil desde quando tais programas apresentam certa convergência de propostas, assumindo um discurso igualitarista, em uma versão menos universalista e mais focalizada, por meio da garantia do acesso ao consumo de serviços. Como visto, esse discurso é temperado com propostas caras ao capital, como a defesa do 'empreendedorismo', a ‘desburocratização’ e a ampliação das parcerias público-privadas. Como se tratam de coligações, incluem partidos de direita, embora estes sejam pequenos e não sejam os líderes. Destarte, o teor liberal dos programas não deve ser atribuído exclusivamente a esses partidos, mas, especialmente, à influência dos setores empresariais, que conseguiram que partidos teoricamente trabalhistas e de centro-esquerda adotassem valores favoráveis ao capital.

Assim, a concepção de cidadania que prevalece é a de uma 'cidadania à la carte', em que direitos são vistos como serviços que podem ser adquiridos no mercado, cabendo ao Estado criar condições para que os que não podem comprá-los diretamente possam vir a comprar um dia, seja pelo aumento do poder aquisitivo (por meio de programas de transferência de renda, aumento de salário, emprego), seja pela garantia do acesso a serviços públicos, em parte gerenciados pelo setor privado. A ação do Estado, assim, não é a garantia de um direito universal, mas uma ajuda circunstancial e temporária, a ser rompida 
quando o cidadão não mais precisar dela.

A penetração desses elementos, claramente liberais, de direita, nos programas dos partidos e coligações que se apresentam como social-democratas, trabalhistas ou socialistas, demonstra não apenas a existência da direita, mas evidencia que essa forma de pensamento, essa ideologia, prescinde da necessidade de um partido próprio na liderança das coligações para divulgar e implementar suas ideias. Obviamente que a direita pode se apresentar como partido, e se apresenta, mas, nos partidos de centro, as tensões entre diferentes segmentos da base permitem a presença relevante desse ideário.

Assim sendo, o centro político se move para a direita, e propostas de centro-esquerda, social-democrata, transformam-se, nesse espectro, em propostas vistas como de extrema-esquerda. Com isso, a defesa de uma perspectiva próxima daquela da RSB parece distante, algo de uma extrema esquerda que não encontra em nenhuma das três candidaturas ampla representação. Fica evidente, especialmente levando-se em conta as propostas de política econômica, que as prioridades estão voltadas à ampliação de consumo, inclusive de planos de saúde, o que é antagônico com a defesa do direito universal à saúde, como prevê o SUS constitucional, tendo em vista que o sistema privado, teoricamente, deveria ser suplementar.

Essas considerações não são um achado original, mas confirmam outros trabalhos que já apontavam, com objetivos diferentes, o transformismo de partidos historicamente de esquerda, como o trabalho de Coelho
(2005) sobre o PT, ou uma tendência de modernização conservadora da sociedade brasileira apontada por Domingues (2002). Mesmo a noção de cidadania à la carte, ou seja, a redução do conceito de cidadania ao consumo de bens e serviços, já havia sido destacada no trabalho de Philip Oxhorn (2010). Entretanto, poder chegar a essas mesmas conclusões, tendo como fontes os programas das coligações partidárias lideradas por partidos que historicamente se apresentam como partidos de centro-esquerda e esquerda, sinaliza uma consolidação dessas perspectivas, já que esses documentos são públicos e têm objetivo de ser usados como parte do marketing das suas concepções e propostas.

Para concluir, cabe ressaltar a importância de atualizar a análise da ação dos partidos políticos no momento atual, uma vez que, após da vitória eleitoral da coligação liderada pelo PT, agravou-se a crise econômica, política, ética e institucional, em que o País continua imerso, contexto no qual o PT perdeu legitimidade e o PMDB, partido que fez parte da coligação vitoriosa, rompeu a aliança e, com apoio da mídia institucionalizada e de setores significativos do grande capital, desencadeou um processo de impedimento da Presidente eleita, adotando medidas que comprometem a viabilidade do SUS constitucional. Levando em conta a reação de amplos setores da sociedade a tais medidas e o debate em torno das perspectivas da esquerda (MARTINS, 2016), cabe destacar, entretanto, a atualidade dos ideais e valores da RSB. 


\section{Referências}

AGENDA Estratégia para a Saúde no Brasil: 5 diretrizes de uma política de saúde 5 estrelas para pobres ou ricos. Brasília, DF: ABRASCO; APSP; CEBES; CFM; CONASEMS; Rede Unida; SBMFC, 2011.

BAHIA, L. O SUS e os desafios da universalização do direito à saúde: tensões e padrões de convivência entre o público e o privado no sistema de saúde brasileiro. In LIMA, N. T. et al. (Org.). Saúde e Democracia: história e perspectivas do SUS. Rio de Janeiro: Fiocruz, 2005.

BAHIA, L., SCHEFFER, M. A Saúde nos programas de governo dos candidatos a Presidente da República do Brasil nas eleições de 2014: notas preliminares para o debate, 2014. Disponível em: < http://apsp. org.br/wp-content/uploads/2014/08/Saude-nasElei\%C3\%A7\%C3\%B5es-2014.pdf>. Acesso em: 23 fev. 2015.

BOBBIO, N. Direita e Esquerda: razões e significados de uma distinção política, 2. ed. São Paulo: Unesp, 2001.

BOSCHI, R.; GAITÁN, F. Neodesenvolvimentismo. In: IVO, A. B. L. (Coord.). Dicionário temático Desenvolvimento e Questão social: 81 problemáticas contemporâneas. São Paulo: Annablum, 2013, p. 325-329.

BRASIL. Justiça Eleitoral. Lista dos Partidos Políticos, das Coligações Partidárias e dos Candidatos Concorrentes: Eleições Gerais 2014 - $1^{\circ}$ Turno. Disponível em: <http://www.justicaeleitoral.jus.br/arquivos/lista-de-candidatos-aptos-por-cargo-e-ordem-alfabetica>. Acesso em: 26 out. 2016.

BRESSER-PEREIRA, L. C.; SPINK, P. Reforma do Estado e administração pública gerencial. Rio de Janeiro: FGV, 1998.

COELHO, E. Uma esquerda para o Capital: Crise do Marxismo e mudanças nos Projetos Políticos dos grupos dirigentes do PT (1979-1998). 2005. 549 f. Tese (Doutorado em História) - Universidade Federal Fluminense, Niterói, 2005.
CONSELHO NACIONAL DE SAÚDE (CNS). 35 anos de luta pela Reforma Sanitária. Saúde em Debate, Rio de Janeiro, v. 35, n. 91, p. 644-649, out./dez. 2011.

. Relatório da $8^{a}$ Conferência Nacional em Saúde. 1986. Disponível em: <http://conselho.saude.gov.br/ biblioteca/Relatorios/relatorio_8.pdf>. Acesso em: 29 jun. 2016.

COSTA, A. M.; BAHIA, L.; SCHEFFER, M. Onde foi parar o sonho do SUS? Le Monde Diplomatique Brasil, São Paulo, v. 69, p. 30-1, 2013. Disponível em: <http:// diplomatique.org.br/onde-foi-parar-o-sonho-do-sus/>. Acesso em: 31 ago. 2017.

DOMINGUES, J. M. A Dialética da Modernização Conservadora e a Nova História do Brasil. Revista de Ciências Sociais, Brasília, DF, v. 45, n. 3, p. 459-482, 2002.

HOCHMAN, G. Saudades do futuro ou um sistema de saúde em tempos democráticos. Cadernos de Saúde Pública, Rio de Janeiro, v. 29, n. 10, p. 1927-1953, out. 2013.

JACOBINA, A. T. O Movimento da Reforma Sanitária Brasileira e sua relação com os Partidos Políticos de matriz marxista. 2016. 217 f. Tese (Doutorado em Saúde Pública) - Instituto de Saúde Coletiva, Universidade Federal da Bahia, Salvador, 2016.

LAMOUNIER, B. Aspectos ideológicos e políticos de nosso país. 2015. Disponível em: <http://globotv.globo. com/globo-news/globo-news-painel/t/globonews-painel/v/painel-os-aspectos-ideologicos-e-politicos-do-nosso-pais/3858960/>. Acesso em: 6 fev. 2015.

MAGNO, L. D. Dos clamores das ruas aos rumores do Congresso: uma análise da conjuntura recente da saúde no Brasil. 2015.105 f. Dissertação (Mestrado em Saúde Coletiva) - Instituto de Saúde Coletiva, Universidade Federal da Bahia, Salvador, 2015.

MARTINS, C. E. Brasil em transe: crise política, golpe de Estado e perspectivas da esquerda. Le 
Monde Diplomatique Brasil, São Paulo, p. 4, jul. 2016. Disponível em: <http://diplomatique.org.br/brasil-em-transe-crise-politica-golpe-de-estado-e-perspectivas-da-esquerda/>. Acesso em: 29 jun. 2017.

MOREIRA, C. A esquerda no Uruguai e no Brasil: cultura política e desenvolvimento partidário. Opin. Pública, Campinas, v. 6, n. 1, p. 17-54, 2000.

OXHORN, P. Cidadania como Consumo ou Cidadania como Agência: uma comparação entre as reformas de democratização da Bolívia e do Brasil. Sociologias, Porto Alegre, v. 12, v. 24, p. 18-43, maio/ago. 2010.

PAIM, J. S. A Constituição Cidadã e os 25 anos do Sistema Único de Saúde (SUS). Cadernos de Saúde Pública, Rio de Janeiro, v. 29, n. 10, p. 1927-1953, out. 2013b.

O futuro do SUS. Cadernos de Saúde Pública, Rio de Janeiro, v. 28, n. 4, p. 612-3, 2012.

Reforma Sanitária Brasileira: contribuição para a compreensão e crítica. Salvador, Edufba; Rio de Janeiro: Editora Fiocruz, 2008.

Reforma Sanitária Brasileira: eppur si muove.

Cadernos de Saúde Pública, Rio de Janeiro, v. 29 n. 10, p. 1927-1953, out. 2013.

PAIM, J. S.; TEIXEIRA, C. F. Configuração institucional e gestão do Sistema Único de Saúde: problemas e desafios. Ciência \&̇ Saúde Coletiva, Rio de Janeiro, v. 12, n. supl., p. 1819-1829, 2007.
RUSCHEINSKY, A. Atores politicos e lutas sociais: movimentos sociais e partidos políticos, Porto Alegre: EdiPUCRS, 1999.

SINGER, A. Cutucando onças com varas curtas. Novos estudos Cebrap, São Paulo, n. 102, p. 42-71, jul. 2015.

TEIXEIRA, C. F.; PAIM, J. S. A política de saúde no Governo Lula e a dialética do menos pior. Saúde em Debate, Rio de Janeiro, v. 29, n. 71, p. 268-283, set./dez. 2005

TEIXEIRA, C. F.; SOUZA, L. E.; PAIM, J. S. Sistema Único de Saúde, a difícil construção de um sistema universal na sociedade brasileira, In: ALMEIDA FILHO, N; PAIM, J. S. (Org.). Saúde Coletiva: teoria e prática. Rio de Janeiro: Medbook, 2014, p. 121-37.

THOMPSON, E. P. A Miséria da Teoria. Rio de Janeiro: Zahar, 1981.

TRIBUNAL SUPERIOR ELEITORAL, (TSE).

Informações sobre as eleições: eleições 2014. Brasília, DF, 2014. Disponível em: <http://www.tse.jus.br/eleicoes/eleicoes-anteriores/eleicoes-2014>. Acesso em: 26 out. 2016

Recebido para publicação em março de 2017

Versão final em agosto de 2017

Conflito de interesses: inexistente

Suporte financeiro: não houve 